\title{
Exploring public health benefits of Dolichos lablab as a dietary supplement during the COVID-19 outbreak: A computational study
}

\author{
Elly Purwanti ${ }^{*}$, Feri Eko Hermanto ${ }^{2}$, Jantje Wiliem Souhaly ${ }^{2}$, Wahyu Prihanta ${ }^{1}$, Tutut Indria Permana ${ }^{1}$ \\ ${ }^{1}$ Department of Educational Biology, Faculty of Teacher Training and Education, University of Muhammadiyah Malang, East Java, Indonesia. \\ ${ }^{2}$ Department of Biology, Faculty of Mathematics and Natural Sciences, Universitas Brawijaya, Malang, East Java, Indonesia.
}

\begin{tabular}{l}
\hline ARTICLE INFO \\
\hline Received on: 04/09/2020 \\
Accepted on: 23/11/2020 \\
Available online: 05/02/2021 \\
\\
\hline Key words: \\
COVID-19, Dolichos lablab, \\
heptad repeat, main Protease, \\
NF-кB.
\end{tabular}

\begin{abstract}
The emerging case of coronavirus disease-19 (COVID-19) caused by the severe acute respiratory syndromecoronavirus (SARS-CoV-2) virus has become a global health issue. Since there is no available developed vaccine, health-promoting foods play a vital role in maintaining the immune system against the disease. Dolichos lablab (DL), an unutilized highly nutritional legume, has an excellent potential to cope with this pandemic with various health benefit phytochemicals. This study appraised the possibility of phytochemical content from DL to prevent virus infection and hyperinflammation in COVID-19 in silico. DL's phytochemicals from liquid chromatography-high-resolution mass spectrometry analysis were docked with several SARS-CoV-2 proteins, including main protease and HR. Also, $\mathrm{NF}-\mathrm{KB}$ docking was executed to pursue anti-inflammatory properties. The drug-likeness properties of screened phytochemicals were then evaluated using SwissADME. According to the results, there were 16 phytochemicals with a high affinity to targeted proteins. Among those, five phytochemicals consistently gave a low binding affinity to all targeted proteins. Those five phytochemicals' physicochemical properties, except for rutin and (9cis)-retinal, also coped with small-molecule bioavailability, permeability, and flexibility according to the SwissADME calculations. In conclusion, DL has a high probability of complementing the medical effort as dietary supplementation to modulate the immune system and prevent viral infection.
\end{abstract}

\section{INTRODUCTION}

The outbreak of coronavirus disease-19 (COVID-19) has now become a significant global health issue. Until the November 2020 update, more than 50 million people have become infected, and over a million have died due to this pandemic (https://covid19. who.int/). This number is still growing day by day, describing the war against COVID-19 as continued. Although several companies already announced that they have proposed vaccine candidates entering the final phase of clinical trials, complementary medicine and dietary intervention still needed to prevent the severity of infected people and prevent healthy people from getting infected (Di Matteo et al., 2020; Panyod et al., 2020). Therefore, exploring

"Corresponding Author

Elly Purwanti, Department of Educational Biology, Faculty of Teacher Training and Education, University of Muhammadiyah Malang,

East Java, Indonesia. E-mail: purwantielly@ymail.com the proper diet for patients or healthy people to help against COVID-19 infection becomes essential.

Thwarting severe acute respiratory syndromecoronavirus (SARS-CoV-2) attachment and replication have become the main target for combating COVID-19 (Jha et al., 2020; McKee et al., 2020). Several proteins from SARS-CoV-2 have been modeled and appropriately studied as a target to decrease the number of positive cases (Dai et al., 2020; Xia et al., 2020; Zhang et al., 2020a). Spike protein is the primary key for SARS-CoV-2 to enter the host's cell, consisting of unique parts called heptad repeat 1 (HR1) and HR2 inside the receptor binding domain (RBD) for performing membrane fusion after attachment (Bosch et al., 2004; Walls et al., 2020; Xia et al., 2020). With this critical role, HR1 and HR2 have been proposed as the main targets to evade viral entry and infection (Xia et al., 2020). Another protein called main protease (MPro) has also become the right candidate due to its vital role in the viral replication and transcription (Hilgenfeld, 2014). Therefore, several studies also used MPro as a target to inhibit 
the severity of the COVID-19 infection (Ahkam et al., 2020; Dai et al., 2020; Jin et al., 2020; Joshi et al., 2020).

Another perspective to support a patient's survival is suppressing massive inflammation in lung tissue (Heck et al., 2020; Zhang et al., 2020b). This inflammation, known as cytokine storms, occurs through the deregulation of the immune response, leading to the disturbance of tissue homeostasis and severe organ damage (Ragab et al., 2020; Soy et al., 2020). Subsequently, injury in the lung tissue gives rise to breathing difficulties and speeds up the patient's death (Acosta and Singer, 2020; Lin et al., 2020). $\mathrm{NF}-\kappa \mathrm{B}$, a kind of transcription factor which controls several cytokines involved in cytokine storms like interleukin- (IL-) 1 and IL-6, has a good starting point to diminish the hyperinflammation (Catanzaro et al., 2020; Conti et al., 2020; Soy et al., 2020). Previously, suppressing NF- $\kappa$ B could increase the survival rate after coronavirus infection (DeDiego et al., 2014). Thus, targeting this transcription factor has a reasonable probability of improving patient survival.

Legumes have been a good source of nutrition for years. However, masses of legume species are still underutilized as nutritious food. One of the rarely used legumes is Dolichos lablab (DL) (Minde et al., 2020). DL not only has a high nutritional content but also has innumerable natural compounds with numerous biological activities. Several bioactive compounds were reported to be contained in DL, including gallic acid, 4-hydroxy3-methoxybenoic acid, p-coumaric acid, ferulic acid, cinnamic acid, catechin, and rutin. Also, saturated and unsaturated fatty acids, terpenoids, and steroids were found as a constituent inside DL beans (Baba et al., 1983; Bahtiar et al., 2017; Habib et al., 2017b; Yoshikawa et al., 1998). Previously, DL was explored for its antioxidant, antidiabetic, antimicrobial, and even antiinflammatory properties (Habib et al., 2017a; Naeem et al., 2020; Rahman and Akhter, 2018; Yin et al., 2018). With those various health benefits, DL is a promising candidate for dietary supplementation to avoid COVID-19 infection.

\section{MATERIAL AND METHOD}

\section{Phytochemical content screening}

Thermo Scientific Dionex Ultimate 3,000 RSLCnano liquid chromatography (LC) coupled with Thermo Scientific Q Exactive Mass Spectrometry (MS) was run to identify the phytochemical content inside the methanolic extract of DL. Hypersil GOLD aQ $50 \times 1 \mathrm{~mm} \times 1.9 \mu$ particle size was installed in the LC instrument as stationary phase, while the mobile phase consists of solvent A ( $0.1 \%$ formic acid in water) and solvent $\mathrm{B}$ ( $0.1 \%$ formic acid in acetonitrile). The LC was operated under the following conditions: flow rate of $40 \mu \mathrm{l} /$ minutes, 30 minutes run time, and $30^{\circ} \mathrm{C}$ column temperature. The obtained data were analyzed using Compound Discoverer with mzCloud in the MS/ MS Library. Compound with mzCloud best matched a score higher than 80 , and then directed for further analysis.

\section{Ligand and protein structures retrieval}

The compounds from liquid chromatography-highresolution mass spectrometry (LC-HRMS) analysis were used as the ligand. The three-dimensional (3D) structure of the ligands was assessed through the PubChem database (Supplementary
File 1). The protein's 3D structures were retrieved from Protein Data Bank (https://www.rcsb.org/), i.e., MPro (PDB ID: 6M2N), HR complex (6LXT), and NF- $\mathrm{BB}$ (1SVC) according to previous studies (Muzaffer et al., 2017; Su et al., 2020; Xia et al., 2020).

\section{Molecular docking}

Water molecules and native ligand from the 3D protein structures were removed using Discovery Studio 16. Energy minimization of the ligand structures was prepared using Open Babel integrated into PyRx 8.0 (O'Boyle et al., 2011). All compounds from LC-HRMS were screened using molecular docking to predict its interaction against protein targets. Proteinligand docking was carried out using AutoDock Vina integrated into PyRx 8.0 (Dallakyan and Olson, 2015; Trott and Olson, 2010) with a maximum grid-size setting. HEX 8.0 was run for protein-protein docking using the default setting and operated under Shape + DARS correlation type (Ritchie and Kemp, 2000). As a comparison, hydroxychloroquine [HCQ, compound identity number (CID): 3,652] (Procacci et al., 2020) and 4,6-dichloro-Nphenyl-1,3,5-triazine-2-amine (NI241, CID: 167,66) (Kobayashi et al., 2016) were employed as a control inhibitor for MPro and $\mathrm{NF}-\kappa \mathrm{B}$, respectively.

\section{Data analysis}

The protein-ligand complex, which has a binding energy lower than $-7 \mathrm{kcal} / \mathrm{mol}$, was directed for further analysis. Interacted residues in each protein-ligand complex and structure conformation were analyzed and visualized using Discovery Studio. The protein structure alignment was executed using PyMOL 2.3.2 with the RMSD value determined as a structural difference among aligned proteins. The alignment was achieved by setting the HR1-HR2 complex as a reference structure.

\section{Prediction of drug-likeness properties}

Drug-likeness properties were analyzed according to Lipinski's Rule of 5 (LRO5) (Lipinski, 2004). Drug resemblance properties were determined using the SwissADME physicochemical properties (Daina et al., 2017), including molecular weight $(\mathrm{MW}), \operatorname{LogP}$ value, the number of $\mathrm{H}$-bond donors, H-bond acceptor, rotatable bond, and total polar surface area (TPSA).

\section{RESULT AND DISCUSSION}

According to the binding affinity, 16 compounds were identified to have biological activities against SARS-CoV-2 infection and inflammation; five of them have a binding energy lower than $-7 \mathrm{kcal} / \mathrm{mol}$ consistently in every target protein. 19-Nortestosterone, mesterolone, oleanolic acid, rutin, and ursolic acid are the compounds that have a low binding energy in MPro, $\mathrm{HR} 1$, and NF- $\kappa \mathrm{B}$. MPro is the protein that can interact with more compounds tested with a binding energy lower than or equal to -7 $\mathrm{kcal} / \mathrm{mol}$. Based on the binding affinity lower than or equal to -7 $\mathrm{kcal} / \mathrm{mol}$, seven compounds could interact with HR1, while six compounds were docked with NF-kB (Table 1).

19-Norandrostenedione, 19-nortestosterone, galaxolidone, mesterolone, oleanolic acid, rutin, and ursolic acid are the compounds that have good affinity to HR1. Attachment of these compounds could alter the HR1-HR2 binding motif represented 
Table 1. Phytochemical with binding energy less than or equal to $-7 \mathrm{kcal} / \mathrm{mol}$ during screening process using molecular docking.

\begin{tabular}{|c|c|c|c|}
\hline \multirow{2}{*}{ Compound } & \multicolumn{3}{|c|}{ Binding energy (kcal/mol) } \\
\hline & HR-1 & MPro & NF-кB \\
\hline (9cis)-Retinal & -6.2 & -7.6 & -5.9 \\
\hline 19-Norandrostenedione & -7.3 & -7.6 & -6.6 \\
\hline 19-Nortestosterone & -7.6 & -7.2 & -7.3 \\
\hline $\begin{array}{l}\text { 3-Hydroxy-3,5,5-trimethyl-4-(3- } \\
\text { oxo-1-buten-1-ylidene)cyclohexyl } \\
\beta \text {-D-glucopyranoside }\end{array}$ & -6.8 & -7.5 & -6.3 \\
\hline Benzoic acid & -6.4 & -7.1 & -5.4 \\
\hline Daidzein & -6.3 & -7.4 & -6.1 \\
\hline Dimethomorph & -6.1 & -8.6 & -6.3 \\
\hline Galaxolidone & -7.4 & -7.8 & -6.3 \\
\hline Ilicic acid & -6.5 & -7.3 & -5.8 \\
\hline Isoquercetin & -6.7 & -8.8 & -6.8 \\
\hline Mesterolone & -7.1 & -7.5 & -7.3 \\
\hline Oleanolic acid & -7.8 & -9.1 & -8.2 \\
\hline Psilostachyin B & -6.2 & -7.7 & -7.1 \\
\hline Rutin & -7.5 & -9.1 & -7.3 \\
\hline Ursolic acid & -8.1 & -9.5 & -7.9 \\
\hline $\begin{array}{l}\text { Hydroxychloroquine (MPro } \\
\text { Inhibitor) }\end{array}$ & - & -6.5 & - \\
\hline NI241 (NF-кB inhibitor) & - & - & -5.4 \\
\hline
\end{tabular}

by declining the HR complex's binding energy after being bonded with those compounds compared to the HR complex without ligand (Fig. 1a). Among the seven compounds that have an excellent affinity to HR1, rutin could modify the HR1-HR2 interaction. This was described by the RMSD value of the HR complex with rutin inside compared to the HR complex alone, which has a greater value than other complexes (Fig. 1b). Interaction of HR1HR2 to form the helix bundle is the crucial step for SARS-CoV-2 membrane fusion (Liu et al., 2004; Ou et al., 2020). Altering the helix bundle formation has been studied to prevent viral entrys (Xia et al., 2020), suggesting that 19-norandrostenedione, 19-nortestosterone, galaxolidone, mesterolone, oleanolic acid, ursolic acid, and in particular rutin have an excellent potency to inhibit viral infection.

MPro is the target protein with plenty of interacted compounds. Compared to HCQ as control, all the compounds have a lower binding energy. Each compound has its favorable binding region, presented by structural visualization (Figure 2) or interacted residues between the ligand molecule and MPro. Among those compounds, only daidzein and (9cis)-retinal have an interaction with catalytic residues of MPro at HIS:41. HCQ did not show any interaction with the catalytic residues (Supplementary File 2). HIS:41 and CYS:145 have been known as essential residues during MPro enzymatic activity (Tahir ul Qamar et al., 2020). Inhibiting these residues has a promising effect on preventing virus replication and prevent viral spreading throughout the tissues (Ahkam et al., 2020; Gyebi et al., 2020; Hosseini-Zare et al., 2020; Tahir ul Qamar et al., 2020).

$\mathrm{NF}-\kappa \mathrm{B}$ is the transcription factor of several proteins related to infection response, including cytokines related to defense mechanisms (Hayden et al., 2006; Schmitz et al., 2014).

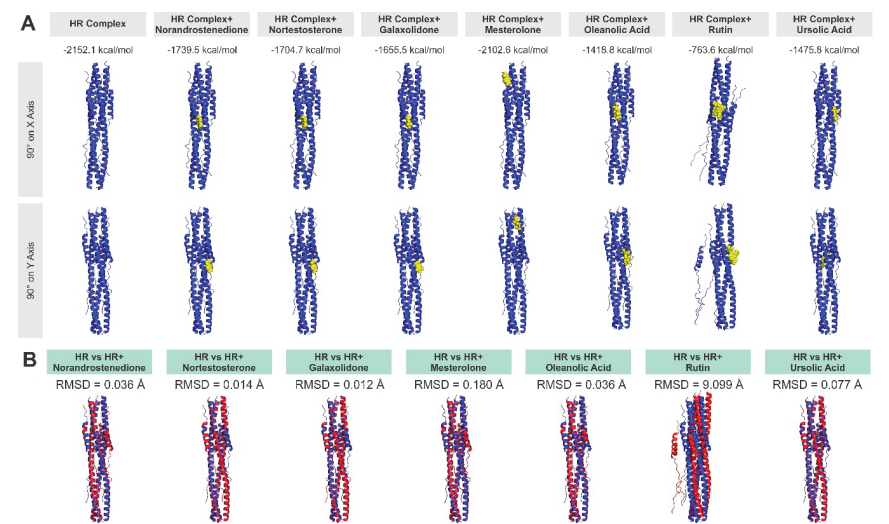

Figure 1. Structural orientation and binding energy of the HR complex after being bound with phytochemical ligands (A) and structural alignment of HR complex before and after being bound with phytochemical ligands (B). The blue ribbons in Figure A represent the HR protein complex, while the yellow spheres describe the phytochemical ligand. In Figure B, the blue ribbons represent the initial form of the HR complex without the ligand, while the red ribbons represent the HR complex structure after being bound with the phytochemical ligands.
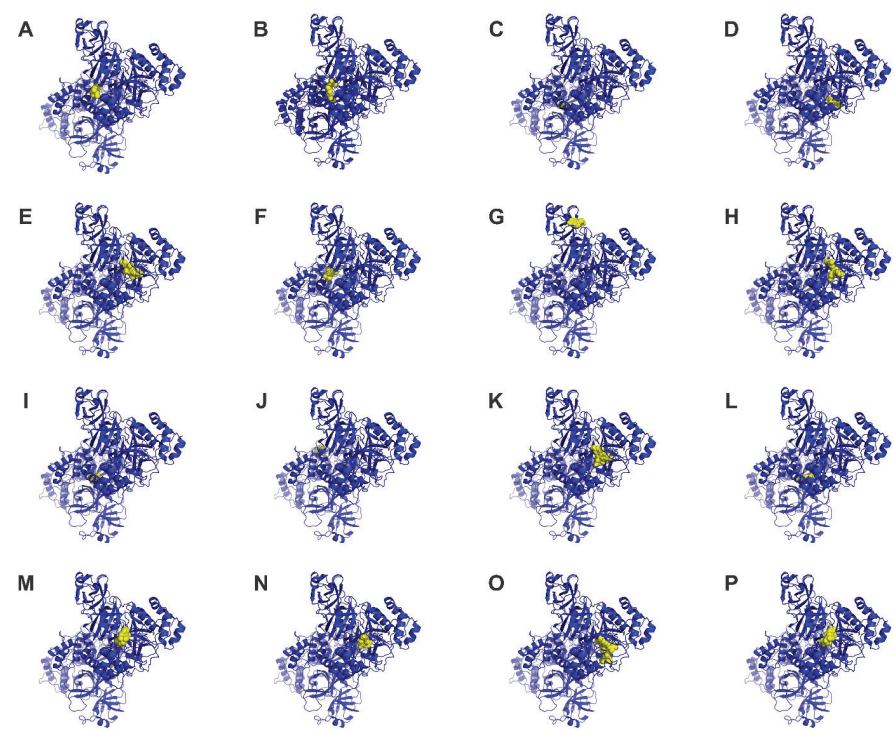

Figure 2. Structural visualization of MPro after being bound with its inhibitor and phytochemical ligands: HCQ (A), (9cis)-retinal (B), 19-norandrostenedione (C), 19-nortestosterone (D), 3-hydroxy-3,5,5-trimethyl-4-(3-oxo-1-buten-1ylidene)cyclohexyl $\beta$-D-glucopyranoside $(\mathrm{E})$, benzoic acid $(\mathrm{F})$, daidzein $(\mathrm{G})$, dimethomorph $(\mathrm{H})$, galaxolidone $(\mathrm{I})$, ilicic acid $(\mathrm{J})$, isoquercetin $(\mathrm{K})$, mesterolone $(\mathrm{L})$, oleanolic acid $(\mathrm{M})$, psilostachyin $\mathrm{B}(\mathrm{N})$, rutin $(\mathrm{O})$, and ursolic acid $(\mathrm{P})$.

At this critical condition, cytokine storms are the main factors that contribute to lung damage due to the overexpression of proinflammatory cytokines (Lin et al., 2020; Soy et al., 2020). Thus, targeting NF- $\kappa \mathrm{B}$ as the main transcription factor for suppressing those cytokines' hyperexpression could play a vital role in augmenting patient survival (Catanzaro et al., 2020). From the docking result, six compounds could interact with $\mathrm{NF}-\kappa \mathrm{B}$ at $-7 \mathrm{kcal} / \mathrm{mol}$ or lower. Although the ligands did not bind with the vital residues involved in NF- $\kappa \mathrm{B}$ DNA-binding site, several interacted amino acids take place adjacent to these binding sites (Figure 3), suggesting their potentials as NF- $\mathrm{BB}$ inhibitors 
Table 2. Physicochemical properties of screened phytochemicals according to SwissADME measurement.

\begin{tabular}{|c|c|c|c|c|c|c|}
\hline Compound & Mol. weight (g/mol) & LogP value & H-bond donor & H-bond acceptor & Rotatable bonds & TPSA \\
\hline (9cis)-Retinal & 464.38 & 2.11 & 8 & 12 & 4 & $210.51 \AA^{2}$ \\
\hline 19-Norandrostenedione & 272.38 & 2.6 & 0 & 2 & 0 & $34.14 \AA^{2}$ \\
\hline 19-Nortestosterone & 274.4 & 2.79 & 1 & 2 & 0 & $37.30 \AA^{2}$ \\
\hline $\begin{array}{l}\text { 3-Hydroxy-3,5,5-trimethyl-4-(3-oxo-1- } \\
\text { buten-1-ylidene)cyclohexyl } \beta \text {-D- } \\
\text { glucopyranoside }\end{array}$ & 386.44 & 2.21 & 5 & 8 & 4 & $136.68 \AA^{2}$ \\
\hline Benzoic acid & 250.33 & 2.74 & 2 & 3 & 3 & $57.53 \AA^{2}$ \\
\hline Daidzein & 254.24 & 1.77 & 2 & 4 & 1 & $70.67 \AA^{2}$ \\
\hline Dimethomorph & 387.86 & 3.67 & 0 & 4 & 6 & $48.00 \AA^{2}$ \\
\hline Galaxolidone & 272.38 & 3.17 & 0 & 2 & 0 & $26.30 \AA^{2}$ \\
\hline Ilicic acid & 252.35 & 2.26 & 2 & 3 & 2 & $57.53 \AA^{2}$ \\
\hline Mesterolone & 304.47 & 3.09 & 1 & 2 & 0 & $37.30 \AA^{2}$ \\
\hline Oleanolic acid & 456.7 & 3.92 & 2 & 3 & 1 & $57.53 \AA^{2}$ \\
\hline Psilostachyin B & 262.3 & 2.17 & 0 & 4 & 0 & $52.60 \AA^{2}$ \\
\hline Quercetin & 284.44 & 3.76 & 0 & 1 & 5 & $17.07 \AA^{2}$ \\
\hline Rutin & 610.52 & 2.43 & 10 & 16 & 6 & $269.43 \AA^{2}$ \\
\hline Ursolic acid & 456.7 & 4.01 & 2 & 3 & 1 & $57.53 \AA^{2}$ \\
\hline
\end{tabular}
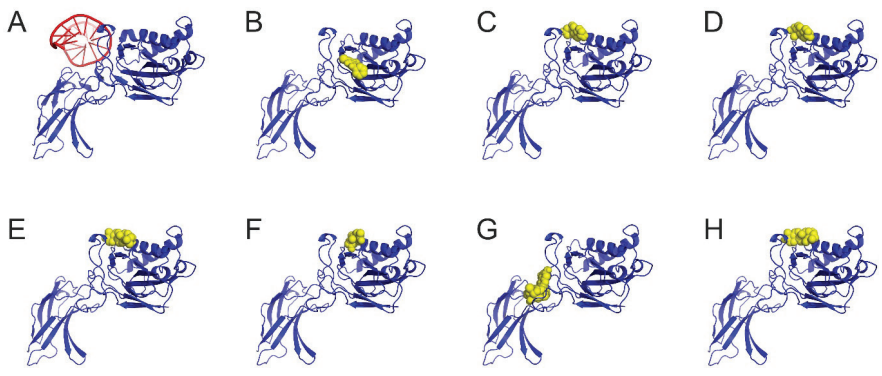

Figure 3. Structural visualization of NF- $\mathrm{KB}$ after being bound with DNA (A), NI241 (B), 19-nortestosterone (C), mesterolone (D), oleanolic acid (E), psilostachyin B (F), rutin $(\mathrm{G})$, and ursolic acid $(\mathrm{H})$.

(Müller et al., 1995). Targeting DNA-binding sites of NF-кB has been employed to preclude chronic inflammation (Gilmore and Herscovitch, 2006; Gupta et al., 2010). Therefore, the presence of those compounds in the NF- $\mathrm{KB}$ DNA-binding domain could reduce hyperinflammation by altering the proinflammatory cytokines' transcription process.

Several criteria have been developed by Lipinski for a small molecule to have good oral bioavailability, permeability, and flexibility (Lipinski, 2004). The oral bioavailability of small molecules is determined by several criteria, including MW, $\log \mathrm{P}$ value, the number of hydrogen bond donors, and acceptor less than $500 \mathrm{~g} / \mathrm{mol}, 5,5$, and 10, respectively (Lipinski, 2004). Also, a molecule with a TPSA value equal or less than $140 \AA$ will carry out good permeability, while the number of rotatable bonds less than 10 represents molecule flexibility (Chagas et al., 2018). Hence, SwissADME was employed to do the calculations related to LRO5. All of the analyzed compounds, except for rutin and (9cis)retinal, have no violations of the MWmolecular weight, $\log \mathrm{P}$ value, $\mathrm{H}$-bond donor, $\mathrm{H}$-bond acceptor, rotatable bonds, and TPSA criteria. Rutin had a low oral bioavailability and permeability with $610.52 \mathrm{~g} / \mathrm{mol}$ of MW, 10 of H-bond donor, 16 of H-bond acceptor, and $269.43 \AA^{2}$ TPSA value. (9cis)-Retinal is also not better than rutin in terms of oral bioavailability and permeability with 8 of H-bond donor, 12 of H-bond acceptor, and $210.51 \AA^{2}$ TPSA value (Table 2).

\section{CONCLUSION}

There are seven herbal compounds from DL, which have good potential as a preventive or complementary agent for COVID-19 treatment based on the constant binding energy lower or equal to $-7 \mathrm{kcal} / \mathrm{mol}$ with MPro or HR1. However, daidzein has better potency as an MPro inhibitor, while rutin showed a worthy effect to prevent viral-host fusion by modifying the HR complex structure orientation. As anti-inflammatory candidates, 19-nortestosterone, mesterolone, oleanolic acid, and ursolic acid have a satisfactory result as NF- $\mathrm{KB}$ inhibitors. Lastly, all compounds with a binding energy lower than or equal to -7 $\mathrm{kcal} / \mathrm{mol}$, except for (9cis)-retinal and rutin, have good oral bioavailability, permeability, and flexibility.

\section{ACKNOWLEDGMENTS}

The authors acknowledge the Ministry of Research, Technology, and Higher Indonesia, the Republic of Indonesia, for funding this research under Grant no. 229/SP2H/LT/DRPM/2019.

\section{AUTHOR CONTRIBUTIONS}

All authors made substantial contributions to conception and design, acquisition of data, or analysis and interpretation of data; took part in drafting the article or revising it critically for important intellectual content; agreed to submit to the current journal; gave final approval of the version to be published; and agree to be accountable for all aspects of the work. All the authors are eligible to be an author as per the international committee of medical journal editors (ICMJE) requirements/guidelines.

\section{CONFLICTS OF INTEREST}

The authors report no financial or any other conflicts of interest in this work. 


\section{ETHICAL APPROVALS}

This study does not involve experiments on animals or human subjects.

\section{PUBLISHER'S NOTE}

This journal remains neutral with regard to jurisdictional claims in published institutional affiliation.

\section{REFERENCES}

Acosta MAT, Singer BD. Pathogenesis of COVID-19induced ARDS: implications for an aging population. Eur Respir J, 2020; 56(3):2002049.

Ahkam AH, Hermanto FE, Alamsyah A, Aliyyah IH, Fatchiyah F. Virtual prediction of antiviral potential of ginger (Zingiber officinale) bioactive compounds against spike and MPro of SARS-CoV2 protein. Berkala Penelitian Hayati J Biol Res, 2020; 25:52-7.

Baba J, Yokota, T, Takahashi N. Brassinolide-related new bioactive steroids from Dolichos lablab seed. Agric Biol Chem, 1983; 47:659-61.

Bahtiar A, Vichitphan K, Han J. Leguminous plants in the Indonesian archipelago: traditional uses and secondary metabolites. Nat Prod Commun, 2017; 12:461-72.

Bosch BJ, Martina, BEE, Van Der Zee R, Lepault J, Haijema, BJ, Versluis C, Heck AJR, De Groot R, Osterhaus ADME, Rottier PJM. Severe acute respiratory syndrome coronavirus (SARS-CoV) infection inhibition using spike protein heptad repeat-derived peptides. Proc Natl Acad Sci U S A, 2004; 101:8455-60.

Catanzaro M, Fagiani F, Racchi M, Corsini E, Govoni S, Lanni C. Immune response in COVID-19: addressing a pharmacological challenge by targeting pathways triggered by SARS-CoV-2. Signal Transduct Target Ther, 2020; 5(1):84.

Chagas CM, Moss S, Alisaraie L. Drug metabolites and their effects on the development of adverse reactions: revisiting lipinski's rule of five. Int J Pharm, 2018; 549:133-49.

Conti P, Ronconi G, Caraffa A, Gallenga C, Ross R, Frydas I, Kritas S. Induction of pro-inflammatory cytokines (IL-1 and IL-6) and lung inflammation by coronavirus-19 (COVI-19 or SARS-CoV-2): antiinflammatory strategies. J Biol Regul Homeost Agents, 2020; 34:327-31.

Dai W, Zhang B, Su H, Li J, Zhao Y, Xie X, Jin Z, Liu F, Li C, Li Y, Bai F, Wang H, Cheng X, Cen X, Hu S, Yang X, Wang J, Liu X, Xiao G, Jiang H, Rao Z, Zhang LK, Xu Y, Yang H, Liu H. Structure-based design of antiviral drug candidates targeting the SARS-CoV-2 main protease. Science, 2020; 368(6497):1331-5

Daina A, Michielin O, Zoete V. SwissADME: a free web tool to evaluate pharmacokinetics, drug-likeness and medicinal chemistry friendliness of small molecules. Sci Rep, 2017; 7:42717.

Dallakyan S, Olson AJ. Small-molecule library screening by docking with PyRx. Methods Mol Biol, 2015; 1263:243-50.

DeDiego ML, Nieto TJL, Regla NJA, Jimenez GJM, Fernandez DR, Fett C, Castaño RC, Perlman S, Enjuanes L. Inhibition of NF-kBMediated Inflammation in severe acute respiratory syndrome coronavirusinfected mice increases survival. J Virol, 2014; 88:913-24.

Di Matteo G, Spano M, Grosso M, Salvo A, Ingallina C, Russo M, Ritieni A, Mannina L. Food and COVID-19: preventive/co-therapeutic strategies explored by current clinical trials and in silico studies. Foods, 2020; 9(8):1036.

Gilmore TD, Herscovitch M. Inhibitors of NF- $\kappa$ B signaling: 785 and counting. Oncogene, 2006; 25:6887-99.

Gupta SC, Sundaram C, Reuter S, Aggarwal BB. Inhibiting $\mathrm{NF}-\kappa \mathrm{B}$ activation by small molecules as a therapeutic strategy. Biochim Biophys Acta, 2010; 1799:775-87.

Gyebi GA, Ogunro OB, Adegunloye AP, Ogunyemi OM, Afolabi SO. Potential inhibitors of coronavirus 3-chymotrypsin-like protease (3CLpro): an in silico screening of alkaloids and terpenoids from African medicinal plants. J Biomol Struct Dyn, 2020; 1-13.
Habib HM, Theuri SW, Kheadr E, Mohamed FE. DNA and BSA damage inhibitory activities, and anti-acetylcholinesterase, anti-porcine $\alpha$-amylase and antioxidant properties of Dolichos lablab beans. Food Funct, $2017 \mathrm{a} ; 8: 881-7$.

Habib HM, Theuri SW, Kheadr EE, Mohamed FE. Functional, bioactive, biochemical, and physicochemical properties of the Dolichos lablab bean. Food Funct, 2017b; 8:872-80.

Hayden MS, West AP, Ghosh S. NF- $\kappa$ B and the immune response. Oncogene, 2006; 25:6758-80.

Heck TG, Ludwig MS, Frizzo MN, Rasia FAA, Homem BPI. Suppressed anti-inflammatory heat shock response in high-risk COVID-19 patients: lessons from basic research (inclusive bats), light on conceivable therapies. Clin Sci (Lond), 2020; 134:1991-2017.

Hilgenfeld R. From SARS to MERS: crystallographic studies on coronaviral proteases enable antiviral drug design. FEBS J, 2014; 281:4085-96.

Hosseini-Zare MS, Thilagavathi R, Selvam C. Targeting severe acute respiratory syndrome-coronavirus (SARS-CoV-1) with structurally diverse inhibitors: a comprehensive review. RSC Adv. 2020; 10:28287-99.

Jha AK, Kumar R, Goenka MK, Dayal VM. Emerging treatment and prevention strategies against COVID-19: a brief update. J Dig Endosc, 2020; 11:69-72.

Jin Z, Du X, Xu Y, Deng Y, Liu M, Zhao Y, Zhang B, Li X, Zhang L, Peng C, Duan Y, Yu J, Wang L, Yang K, Liu F, Jiang R, Yang, Xinglou, You T, Liu, Xiaoce, Yang, Xiuna, Bai F, Liu H, Liu, Xiang, Guddat LW, Xu W, Xiao G, Qin C, Shi Z, Jiang H, Rao Z, Yang H. Structure of M pro from SARS-CoV-2 and discovery of its inhibitors. Nature, 2020; 582:289-93.

Joshi RS, Jagdale SS, Bansode SB, Shankar SS, Tellis MB, Pandya VK, Chugh A, Giri AP, Kulkarni MJ. Discovery of potential multitarget-directed ligands by targeting host-specific SARS-CoV-2 structurally conserved main protease. J Biomol Struct Dyn, 2020; 1-16.

Kobayashi T, Tanuma S, Kino K, Miyazawa H. New scaffolds of inhibitors targeting the DNA binding of NF- $\mathrm{KB}$. Integr Mol Med, 2016; 3(5):769-73.

Lin S, Zhao Y, Zhou D, Zhou F, Xu F. Coronavirus disease 2019 (COVID-19): cytokine storms, hyper-inflammatory phenotypes, and acute respiratory distress syndrome. Genes Dis, 2020.

Lipinski CA. Lead- and drug-like compounds: the rule-of-five revolution. Drug Discov Today Technol, 2004; 1:337-41.

Liu S, Xiao G, Chen Y, He Y, Niu J, Escalante CR, Xiong H, Farmar J, Debnath AK, Tien P, Jiang S. Interaction between heptad repeat 1 and 2 regions in spike protein of SARS-associated coronavirus: implications for virus fusogenic mechanism and identification of fusion inhibitors. Lancet, 2004; 363:938-47.

McKee DL, Sternberg A, Stange U, Laufer S, Naujokat C. Candidate drugs against SARS-CoV-2 and COVID-19. Pharmacol Res, 2020; $157: 104859$.

Minde JJ, Venkataramana PB, Matemu AO. Dolichos Lablab-an underutilized crop with future potentials for food and nutrition security: a review. Crit Rev Food Sci Nutr, 2020; 1-13.

Müller CW, Rey FA, Sodeoka M, Verdine GL, Harrison SC Structure of the NF-kappa B p50 homodimer bound to DNA. Nature, 1995; 373:311-7.

Muzaffer U, Paul VI, Rajendra PN. Molecular docking of selected phytoconstituents with signaling molecules of Ultraviolet-B induced oxidative damage. In Silico Pharmacol, 2017; 5(1):17.

Naeem M, Shabbir A, Ansari AA, Aftab T, Khan MMA, Uddin M. Hyacinth bean (Lablab purpureus L.) - an underutilised crop with future potential. Sci Hortic, 2020; 272:109551.

O'Boyle NM, Banck M, James CA, Morley C, Vandermeersch T, Hutchison GR. Open babel: an open chemical toolbox. J Cheminform, $2011 ; 3: 33$.

Ou X, Liu Y, Lei X, Li P, Mi D, Ren L, Guo L, Guo R, Chen T, Hu J, Xiang Z, Mu Z, Chen X, Chen J, Hu K, Jin Q, Wang J, Qian Z. Characterization of spike glycoprotein of SARS-CoV-2 on virus entry and its immune cross-reactivity with SARS-CoV. Nat Commun, 2020; 11:1620. 
Panyod S, Ho CT, Sheen LY. Dietary therapy and herbal medicine for COVID-19 prevention: a review and perspective. J Tradit Complement Med, 2020; 10:420-7.

Procacci P, Macchiagodena M, Pagliai M, Guarnieri G, Iannone F. Interaction of hydroxychloroquine with SARS-CoV2 functional proteins using all-atoms non-equilibrium alchemical simulations. Chem Commun (Camb.), 2020; 56: 8854-6.

Ragab D, Salah Eldin H, Taeimah M, Khattab R, Salem R. The COVID-19 cytokine storm; What We Know So Far. Front Immunol, 2020; $11: 1446$.

Rahman SA, Akhter MS. Antibacterial and cytotoxic activity of seeds of white hyacinth bean (Lablab purpureus L. sweet 'white' ) -. J Adv Biotechnol Exp Ther, 2018; 1:49-54.

Ritchie, DW, Kemp, GJ. Protein docking using spherical polar Fourier correlations. Proteins, 2000; 39:178-94.

Schmitz ML, Kracht M, Saul VV. The intricate interplay between RNA viruses and NF- $\kappa$ B. Biochim Biophys Acta, 2014; 1843(11):2754-64.

Soy M, Keser G, Atagündüz P, Tabak F, Atagündüz I, Kayhan S. Cytokine storm in COVID-19: pathogenesis and overview of antiinflammatory agents used in treatment. Clin Rheumatol, 2020; 39:2085-94.

Su H, Yao S, Zhao W, Li M, Liu J, Shang W, Xie H, Ke C, Hu H, Gao M, Yu K, Liu H, Shen J, Tang W, Zhang L, Xiao G, Ni L, Wang D, Zuo J, Jiang H, Bai F, Wu Y, Ye Y, Xu Y. Anti-SARS-CoV-2 activities in vitro of shuanghuanglian preparations and bioactive ingredients. Acta Pharmacol Sin, 2020; 41:1167-77.

Tahir QM, Alqahtani SM, Alamri MA, Chen, LL. Structural basis of SARS-CoV-2 3CLpro and anti-COVID-19 drug discovery from medicinal plants. J Pharm Anal, 2020; 10:313-9.

Trott O, Olson AJ. AutoDock Vina: improving the speed and accuracy of docking with a new scoring function, efficient optimization and multithreading. J Comput Chem, 2010; 31:455-461.

Walls AC, Park, YJ, Tortorici MA, Wall A, McGuire AT, Veesler D. Structure, function, and antigenicity of the SARS-CoV-2 spike glycoprotein. Cell, 2020; 181:281-92.
Xia S, Liu M, Wang C, Xu W, Lan Q, Feng S, Qi F, Bao L, Du L, Liu S, Qin C, Sun F, Shi Z, Zhu Y, Jiang S, Lu L. Inhibition of SARS-CoV-2 (previously 2019-nCoV) infection by a highly potent pan-coronavirus fusion inhibitor targeting its spike protein that harbors a high capacity to mediate membrane fusion. Cell Res, 2020; 30:343-55.

Yin J, Seo CS, Hwang IH, Lee MW, Song KH. Anti-obesity activities of chikusetsusaponin IVa and Dolichos lablab L. Seeds. Nutrients, 2018; 10:1221.

Yoshikawa M, Murakami T, Komatsu H, Matsuda H. Medicinal foodstuffs. XII. Saponin constituents with adjuvant activity from hyacinth bean, the seeds of Dolichos lablab L. (1): structures of lablabosides A, B, and C. Chem Pharm Bull (Tokyo), 1998; 46: 812-6.

Zhang L, Lin D, Sun X, Curth U, Drosten C, Sauerhering L, Becker S, Rox K, Hilgenfeld R. Crystal structure of SARS-CoV-2 main protease provides a basis for design of improved $\alpha$-ketoamide inhibitors. Science, 2020a; 368:409-12.

Zhang W, Zhao Y, Zhang F, Wang Q, Li T, Liu Z, Wang J, Qin Y, Zhang X, Yan X, Zeng X, Zhang S. The use of anti-inflammatory drugs in the treatment of people with severe coronavirus disease 2019 (COVID-19): the Perspectives of clinical immunologists from China. Clin Immunol, 2020b; 214:108393.

\section{How to cite this article:}

Purwanti E, Hermanto FE, Souhaly JW, Prihanta W, Permana TI. Exploring public health benefits of Dolichos lablab as a dietary supplement during the COVID-19 outbreak: A computational study. J Appl Pharm Sci, 2021; 11(02):135-140. 